\title{
Transfusion characteristics and hemostatic conditions in octogenarians undergoing emergency surgery for acute aortic dissection: a retrospective study
}

\author{
Tetsuhito Masubuchi ${ }^{1}$, Kenji Yoshitani ${ }^{1 *}$ D, Kimito Minami ${ }^{1}$, Chisaki Yokoyama ${ }^{1}$, Akito Tsukinaga',
}

Takahisa Goto ${ }^{2}$ and Yoshihiko Ohnishi

\begin{abstract}
Background: The number of elderly patients undergoing elective as well as emergent cardiac surgery is increasing. Octogenarian and older patients undergoing surgery for acute type A aortic dissection (AAD) have a significantly higher risk of postoperative mortality than younger patients. Hemostasis is difficult in octogenarians with AAD. However, few studies have investigated perioperative blood transfusion volumes and hemostatic conditions in patients undergoing AAD surgery. We retrospectively investigated whether these factors differed between octogenarians and younger patients with AAD.
\end{abstract}

Methods: The records of 207 patients who underwent emergency surgery for AAD were reviewed between 2008 and 2014. We compared the total volumes of transfused blood components (red blood cell concentrate, fresh frozen plasma, platelets concentrate, and cryoprecipitate), perioperative blood coagulation test results (prothrombin time-international normalized ratio, activated partial thrombin time, and activated coagulation time), and intensive care unit and hospital stay durations between octogenarians $(n=33)$ and patients $<80$ years old $(n=170)$.

Results: A significantly greater volume of red blood cell concentrates was transfused in octogenarians than in patients $<80$ years old. Isolated prolonged activated partial thromboplastin time was observed in octogenarian patients. Duration of hospital stays was significantly longer in octogenarians than in patients $<80$ years old.

Conclusions: Octogenarians required more red blood cells during surgery for AAD and exhibited isolated APTT prolongation.

Keywords: Octogenarian, Acute aortic dissection, Hemostasis

\section{Background}

Major surgery is becoming more common in octogenarians as societies worldwide experience rapid aging. The number of elderly patients undergoing elective as well as emergent cardiac surgery is increasing. Acute type A aortic dissection (AAD) is a severe, life-threatening

\footnotetext{
* Correspondence: ykenji@kfz.biglobe.ne.jp

'Department of Anesthesiology, National Cerebral and Cardiovascular Center, 6-1, Kishibeshimmachi, Suita, Osaka 564-8565, Japan

Full list of author information is available at the end of the article
}

condition that is associated with high hospital mortality (15-30\%) [1]. Biancari et al. [2] suggested in a systematic review and meta-analysis that octogenarian and older patients with type A aortic dissection had a significantly higher risk of postoperative mortality than younger patients. Previous studies have shown that operation duration, cardiopulmonary bypass time, and blood transfusion volumes are independent risk factors for mortality in patients with AAD [3, 4]. Clinically, it is often difficult to achieve hemostasis in octogenarians 
with AAD. However, few studies have investigated perioperative blood transfusion volumes and hemostatic conditions in patients undergoing AAD surgery. In this study, we retrospectively investigated whether octogenarians with AAD differed from younger patients in regard to these factors.

\section{Methods}

We retrospectively reviewed the clinical records and data of patients who underwent surgical treatment for AAD from January 2008 to December 2014. The exclusion criterion was prior thoracic endovascular aortic repair. The study protocol was approved by our institutional review board (17 April 2015, M27002), and the need for written informed consent was waived due to the retrospective nature of the study. We collected data on the following clinical characteristics: height; weight; levels of hemoglobin and serum creatinine; estimated glomerular filtration rate (eGFR); perioperative blood coagulation tests; intraoperative transfusion volumes of red blood cell concentrate (RCC), fresh frozen plasma (FFP), platelet concentrate $(\mathrm{PC})$, and cryoprecipitate; and durations of intensive care unit (ICU) and hospital stays. Perioperative blood coagulation tests included prothrombin time-international normalized ratio (PT-INR), activated partial thromboplastin time (APTT), serum fibrinogen concentration, and platelet count. All data were collected at four time points: (1) preoperatively, (2) after protamine administration, (3) at the end of the operation, and (4) at ICU admission. Patients with preoperative hemodialysis were excluded in this study.

\section{Statistical analysis}

All variables are expressed as median (interquartile range). In regard to blood coagulation tests, intragroup differences between patients aged $<80$ and $\geq 80$ years were examined using a multivariable linear regression model that included a cross-product term between the elapsed time and either age $\geq 80$ or $<80$ years. This model used the Huber-White method. Statistically significant results indicated that time-series variations of PT, APTT, fibrinogen, and platelet counts differed depending on the age group. To clarify factors affecting total transfusion volumes, backward stepwise multivariable regression analysis was performed. Factors affecting total transfusion volume included age $\geq 80$, body weight, eGFR, preoperative hemoglobin concentration, the lowest hemoglobin concentration during cardiopulmonary bypass $(\mathrm{CPB})$, and $\mathrm{CPB}$ duration which were reported in previous studies [5-8]. The threshold for significance was $P<0.05$. Data were analyzed using STATA SE15 and R-3.6.1.

\section{Results}

The records of 207 patients who underwent emergency operations from 2008 to 2014 were reviewed. Of these patients, $33(16 \%)$ were octogenarians and 174 (84\%) were aged < 80 years. Baseline data (Table 1) showed that compared to non-octogenarians, octogenarians were shorter, weighed less, and had a lower preoperative hemoglobin concentration and eGFR.

Details regarding total intraoperative transfusion volumes are shown in Table 2. A significantly greater volume of RCCs was transfused in octogenarians than in patients aged $<80$ years. The results of blood coagulation tests are shown in Fig. 1a-d. Regression models that included an interaction term showed that PT-INR, APTT, fibrinogen, and platelet count were modified depending on age group (Fig. 1a-d; $n=$ 118). There was a significant difference in APTT between the age groups ( $P$ for interaction of APTT $=$ 0.034). Hospital stay durations in octogenarians were significantly longer than those in younger patients (Table 3).

The results of multivariable regression analysis are shown in Table 4. CPB duration, preoperative

Table 1 Patient characteristics and intraoperative data of the group, age $<80$ years old and age $\geqq 80$ years old

\begin{tabular}{|c|c|c|c|}
\hline & $\begin{array}{l}\text { Age } \geqq 80 y r \\
(n=33)\end{array}$ & $\begin{array}{l}\text { Age }<80 y r \\
(n=174)\end{array}$ & $P$ value \\
\hline Height (cm) & $150(145,153)$ & $\begin{array}{l}160 \\
(154,170)\end{array}$ & $\begin{array}{l}< \\
0.001\end{array}$ \\
\hline Weight (kg) & $48(42,50)$ & $60(51,70)$ & $\begin{array}{l}< \\
0.001\end{array}$ \\
\hline Sex (male/female) & $6 / 27$ & $93 / 81$ & 0.001 \\
\hline Preoperative hemoglobin (g/dL) & $10.6(9.8,11.7)$ & $\begin{array}{l}12.3 \\
(11,13.3)\end{array}$ & $\begin{array}{l}< \\
0.001\end{array}$ \\
\hline Preoperative platelet $\left(\times 10^{3} \mu \mathrm{L}\right)$ & $132(107,180)$ & $\begin{array}{l}161 \\
(127,199)\end{array}$ & 0.023 \\
\hline Fibrinogen (mg/dL) & $\begin{array}{l}239.5(191.5 \\
293)\end{array}$ & $\begin{array}{l}246 \\
(191,309)\end{array}$ & 0.60 \\
\hline Preoperative PT-INR & $\begin{array}{l}1.03(0.97 \\
1.25)\end{array}$ & $\begin{array}{l}1.03 \\
(0.98,1.14)\end{array}$ & 0.50 \\
\hline Preoperative APTT (second) & $\begin{array}{l}32.5(27.5 \\
39.5)\end{array}$ & $\begin{array}{l}31(27.5 \\
36)\end{array}$ & 0.34 \\
\hline sCre (mg/dL) & $\begin{array}{l}0.84(0.73 \\
1.52)\end{array}$ & $\begin{array}{l}0.87 \\
(.67,1.09)\end{array}$ & 0.23 \\
\hline $\operatorname{eGFR}\left(\mathrm{ml} / \mathrm{min} / 1.73 \mathrm{~m}^{2}\right)$ & $\begin{array}{l}51.2(28.4 \\
60.8)\end{array}$ & $\begin{array}{l}62.1 \\
(45.9,76.4)\end{array}$ & $\begin{array}{l}< \\
0.001\end{array}$ \\
\hline $\begin{array}{l}\text { Lowest hemoglobin during CPB } \\
(\mathrm{g} / \mathrm{dL})\end{array}$ & $7.3(6.9,7.6)$ & $7.5(6.9,8)$ & 0.22 \\
\hline CPB duration (min) & $193(169,232)$ & $\begin{array}{l}215.5 \\
(172,272)\end{array}$ & 0.18 \\
\hline
\end{tabular}

Data were expressed as median (interquartile range)

$A P T T$ activated partial thromboplastin time, CPB cardiopulmonary bypass, eGFR estimated glomerular filtration rate, $P T-I N R$ prothrombin time-international normalized ratio, sCre serum creatinine, $Y r$ years old 
Table 2 Total transfusion volumes

\begin{tabular}{llll}
\hline & Age $\geq 80 \mathrm{yr}$ & Age $<80 \mathrm{yr}$ & $P$ value \\
\hline RCC $(\mathrm{mL})$ & $3886(1940)$ & $3005(2010)$ & 0.021 \\
FFP $(\mathrm{mL})$ & $2720(1311)$ & $2743(1896)$ & 0.94 \\
PC $(\mathrm{mL})$ & $906(382)$ & $799(394)$ & 0.15 \\
Cryoprecipitate $(\mathrm{mL})$ & $95(129)$ & $70(97)$ & 0.21 \\
Total transfusion volume $(\mathrm{mL})$ & $7607(3430)$ & $6618(4048)$ & 0.19 \\
\hline
\end{tabular}

FFP fresh frozen plasma, $P C$ platelet concentrate, $R C C$ red blood cell concentrate, $y r$ years old

hemoglobin concentration, and age $\geq 80$ were significantly associated with total transfusion amount.

\section{Discussion}

In this study, octogenarian patients undergoing surgery for AAD required a greater RCC transfusion volume. Isolated prolonged APTT was observed in octogenarian patients. Hospital stay durations in octogenarians were significantly longer than in patients aged $<80$ years.

As lifespans have grown longer, the number of acute aortic repair operations performed in octogenarian patients has increased. A recent meta-analysis reported that octogenarian and older patients with AAD had a significantly higher risk of postoperative mortality than younger patients [2]. However, surgical intervention for aortic arch disease in octogenarians can yield satisfactory early clinical outcomes and mortality and morbidity rates during hospitalization, and a non-randomized controlled study demonstrated acceptable mid-term survival with adequate daily activity [9]. Therefore, we need to clarify risk factors in this population to avoid unwanted outcomes.

Massive intraoperative bleeding is a serious problem during the aortic repair of acute aortic dissection, since this procedure requires complicated aortic anastomosis and prolonged cardiopulmonary bypass time. Serious bleeding increases the duration of the operation and results in an increased requirement for transfusion of allogeneic blood products.

In this study, age $\geq 80$ years was significantly associated with total transfusion amount, a result that was compatible with those of previous reports [1, 10]. Regarding specific blood components, octogenarian patients required a significantly greater volume of RCC than patients aged $<80$ years and also
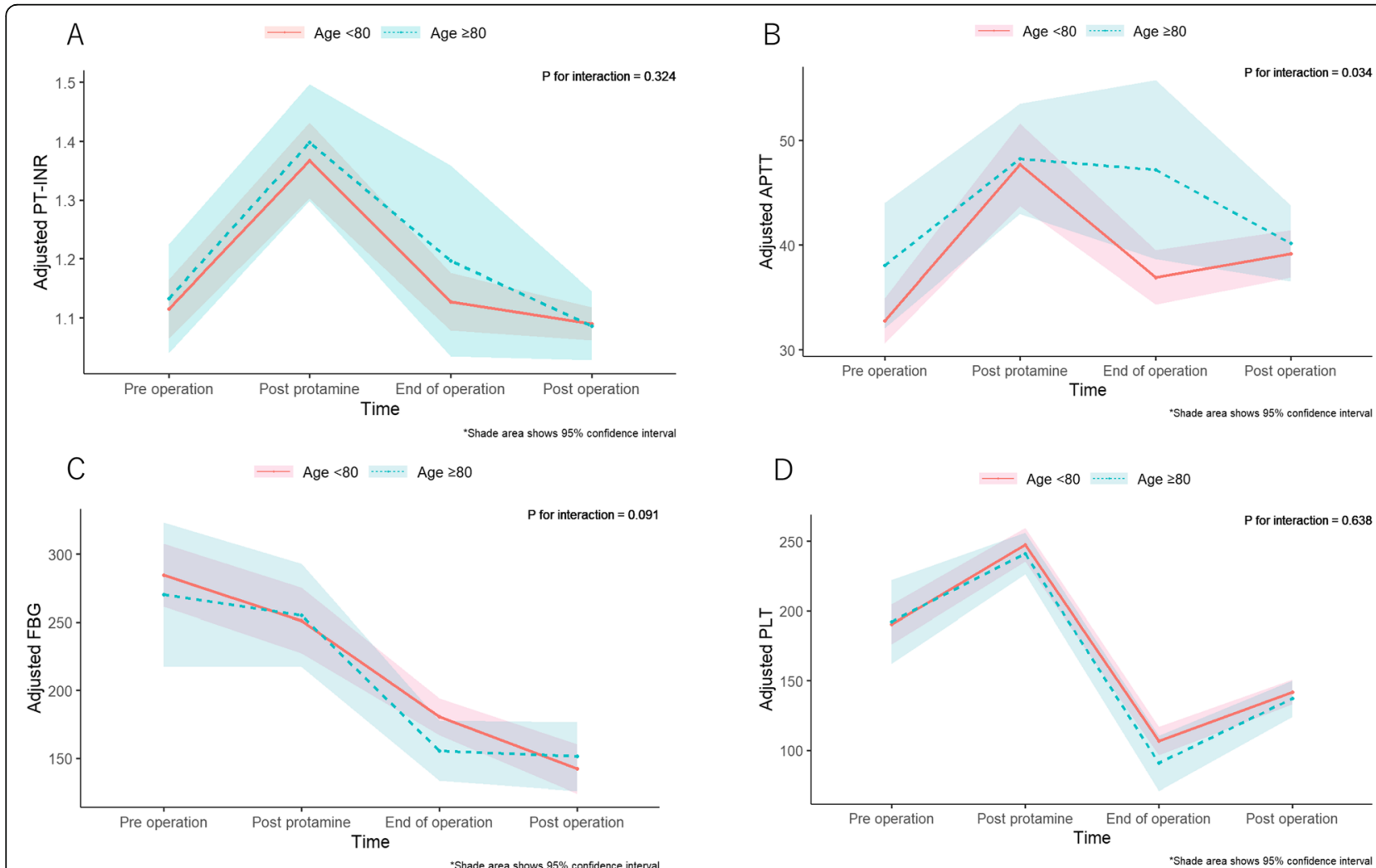

Fig. 1 Interaction analysis between elapsed time and a prothrombin time-international normalized ratio (PT-INR), b activated partial thrombin time (APTT), c fibrinogen concentration (FBG), and $\mathbf{d}$ platelet count (PLT). PT-INR, APTT, FBG, and PLT were adjusted for eGFR, sex, and body weight 
Table 3 Lengths of intensive care unit and hospital stays

\begin{tabular}{llll}
\hline & $\begin{array}{l}\text { Age } \geq 80 \mathrm{yr} \\
(n=33)\end{array}$ & $\begin{array}{l}\text { Age }<80 \mathrm{yr} \\
(n=174)\end{array}$ & $P$ value \\
\hline ICU stay (days) & $6(5,12)$ & $5(4,7)$ & 0.055 \\
Hospital stay (days) & $36(26,52)$ & $26(21,36)$ & 0.007 \\
\hline
\end{tabular}

Data were expressed as median (interquartile range); yr: years old.

demonstrated a significantly lower preoperative hemoglobin concentration. As shown by multivariable regression analysis, preoperative hemoglobin concentration influenced the volume of transfused RCC. Acute aortic dissection consumes red blood cells, coagulation factors, and platelets to facilitate thrombus formation in the pseudo-lumen. The lower preoperative hemoglobin concentration in octogenarians can be explained by their lower body weight. Furthermore, aging leads to unexplained anemia, probably due to pathological processes such as progressive resistance of bone marrow erythroid progenitors to erythropoietin and a chronic, subclinical pro-inflammatory state [11]. Thus, octogenarians are particularly at risk of massive bleeding in acute aortic dissection.

In this study, the APTT was prolonged in octogenarian patients. The APTT reflects the function of the intrinsic pathway, which depends on factors VIII, IX, XI, and XII. A prolonged APTT with normal PT can be caused by one or more of the following: deficiencies in any of the components of the intrinsic pathway, the presence of the lupus anticoagulant or acquired inhibitors of coagulation, systemic anticoagulation (most often with heparin), and von Willebrand disease [12]. After cardiopulmonary bypass, residual heparin and reduced von Willebrand factor (VWF) may cause isolated prolonged APTT. However, many studies have shown that VWF levels are elevated in elderly populations [13-15]. Zindovic and colleagues reported that in acute aortic dissection, VWF activity just before the end of surgery was unchanged compared to preoperative levels [16]. VWF may not be associated with higher levels of APTT just after the administration of protamine.

Regarding residual heparin, APTT is more sensitive than ACT to low-dose unfractionated heparin activity

Table 4 Factors affecting total transfusion amounts

\begin{tabular}{llll}
\hline & Coefficient & $P$ value & $\begin{array}{l}95 \% \text { confidence } \\
\text { interval }\end{array}$ \\
\hline CPB duration (min) & 1.545 & $<$ & 13 to 19 \\
& & 0.001 & \\
Preoperative hemoglobin & -335 & $<$ & -499 to -220 \\
concentration $(\mathrm{g} / \mathrm{dL})$ & & 0.001 & \\
Age $\geq 80$ years & 768 & 0.044 & 1932 to 4962 \\
\hline
\end{tabular}

$C P B$ cardiopulmonary bypass
[17]. Low-dose heparin may result in isolated prolonged APTT in octogenarians. Unfractionated heparin is eliminated by binding to macrophages and endothelial cells and by clearance from the bloodstream by the kidneys, the latter of which is a slower process [18]. In this study, eGFR was significantly lower in octogenarians than in patients aged $<80$ years. Decreased eGFR may be caused by structural and functional changes that occur with aging in individuals with vascular disease [19] and may be associated with isolated prolonged APTT in octogenarians.

In this study, hospital stay durations were significantly longer in octogenarians with acute aortic dissection. These results are compatible with those of a previous study [20]. Octogenarians may have various complications that can affect the lengths of hospital stays.

There are several limitations to this study. First, it was retrospective in nature, and the patient number was small because eligible patients received emergency surgery. We could not analyze the total volume of intraoperative bleeding due to lack of data and data inaccuracy. As a result, we analyzed total transfusion volume, which may be a surrogate for the total volume of intraoperative bleeding. Second, we did not have a unified protocol for transfusion in the setting of acute aortic dissection. The transfusion volumes of RCC, FFP, and platelets depended on the decisions of attending anesthesiologists, and this may have affected the total transfusion volume. Third, we could not get the data on whether patients had antiplatelet and anticoagulant drugs due to emergency surgery. There might be confounders about preoperative unrecognized hemostatic condition. However, we need to manage AAD without the information of hemostatic condition in most of the case. We believe our finding may help in managing AAD cases.

\section{Conclusion}

During aortic repair of acute aortic dissection, octogenarians demonstrated a greater volume of transfused RCC than patients aged $<80$ years and exhibited APTT prolongation.

\section{Abbreviations}

AAD: Acute type A aortic dissection; APTT: Activated partial thromboplastin time; eGFR: Estimated glomerular filtration rate; FFP: Fresh frozen plasma; ICU: Intensive care unit; PC: Platelet concentrate; PT-INR: Prothrombin timeinternational normalized ratio; RCC: Red blood cell concentrate; WWF: von Willebrand factor

\section{Acknowledgements}

We thanked for the statistical advice from Michikazu Nakai, Department of Statistics, National Cerebral and Cardiovascular Center. 


\section{Implication statement}

We retrospectively investigated whether transfusion and hemostatic conditions differed between octogenarians and younger patients with acute aortic dissection. Octogenarians required more red blood cells during surgery for AAD and exhibited isolated APTT prolongation.

\section{Authors' contributions}

Tetsuhito Masubuchi: writing manuscript. Kenji Yoshitani: revising the manuscript. Kimito Minami: statistical analysis. Chisaki Yokoyama: data collection, statistical analysis. Akito Tsukinaga: data collection, statistical analysis. Takahisa Goto: management of the study. Yoshihiko Ohnishi: management of the study. The authors read and approved the final manuscript.

\section{Funding}

This research was funded by department funding (Base-33).

\section{Availability of data and materials}

The datasets used and analyzed during the current study are available from the corresponding author on reasonable request

\section{Competing interest}

Declarations of interest: none.

\section{Ethics approval and consent to participate}

The study protocol was approved by our institutional review board (17 April 2015, M27-002), and the need for written informed consent was waived due to the retrospective nature of the study.

\section{Consent for publication}

No individual person's data was included.

\section{Author details}

'Department of Anesthesiology, National Cerebral and Cardiovascular Center, 6-1, Kishibeshimmachi, Suita, Osaka 564-8565, Japan. ${ }^{2}$ Department of Anesthesiology, Yokohama City University Hospital, 3-9, Fukuura, Yokohama, Kanagawa 236-0004, Japan.

Received: 26 May 2020 Accepted: 3 July 2020

Published online: 09 July 2020

\section{References}

1. Tochii M, Takami Y, Hattori K, Ishikawa H, Ishida M, Higuchi Y, Takagi Y. Early and late outcomes of surgical repair for Stanford A acute aortic dissection in octogenarians. Circ J. 2016;80(12):2468-72

2. Biancari $F$, Vasques $F$, Benenati $V$, Juvonen $T$. Contemporary results after surgical repair of type $A$ aortic dissection in patients aged 80 years and older: a systematic review and meta-analysis. Eur J Cardiothorac Surg. 2011; 40(5):1058-63.

3. Conzelmann LO, Weigang E, Mehlhorn U, Abugameh A, Hoffmann I, Blettner M, Etz CD, Czerny M, Vahl CF, Investigators G. Mortality in patients with acute aortic dissection type A: analysis of pre- and intraoperative risk factors from the German Registry for Acute Aortic Dissection Type A (GERA ADA). Eur J Cardiothorac Surg. 2016:49(2):e44-52.

4. Dib B, Seppelt PC, Arif R, Weymann A, Veres G, Schmack B, Beller CJ, Ruhparwar A, Karck M, Kallenbach K. Extensive aortic surgery in acute aortic dissection type A on outcome - insights from 25 years single center experience. J Cardiothorac Surg. 2019;14(1):187.

5. Goudie R, Sterne JA, Verheyden V, Bhabra M, Ranucci M, Murphy GJ. Risk scores to facilitate preoperative prediction of transfusion and large volume blood transfusion associated with adult cardiac surgery. Br J Anaesth. 2015; 114(5):757-66

6. Huang D, Chen C, Ming Y, Liu J, Zhou L, Zhang F, Yan M, Du L. Risk of massive blood product requirement in cardiac surgery: a large retrospective study from 2 heart centers. Medicine (Baltimore). 2019;98(5):e14219.

7. Isil CT, Yazici P, Bakir I. Risk factors and outcome of increased red blood cell transfusion in cardiac surgical patients aged 65 years and older. Thorac Cardiovasc Surg. 2015;63(1):39-44.

8. Karkouti K, O'Farrell R, Yau TM, Beattie WS. Reducing Bleeding in Cardiac Surgery Research G. Prediction of massive blood transfusion in cardiac surgery. Can J Anaesth. 2006;53(8):781-94.
9. Kurazumi H, Mikamo A, Kudo T, Suzuki R, Takahashi M, Shirasawa B, Zempo $\mathrm{N}$, Hamano K. Aortic arch surgery in octogenarians: is it justified? Eur J Cardiothorac Surg. 2014;46(4):672-7.

10. Suenaga $\mathrm{E}$, Sato $\mathrm{M}$, Fumoto $\mathrm{H}$. Ascending aortic replacement for acute type A aortic dissection in octogenarians. Gen Thorac Cardiovasc Surg. 2016; 64(3):138-43.

11. Cappellini MD, Motta I. Anemia in clinical practice-definition and classification: does hemoglobin change with aging? Semin Hematol. 2015; 52(4):261-9.

12. Loizou E, Mayhew DJ, Martlew V, Murthy BVS. Implications of deranged activated partial thromboplastin time for anaesthesia and surgery. Anaesthesia. 2018;73(12):1557-63.

13. Franchini M. Hemostasis and aging. Crit Rev Oncol Hematol. 2006;60(2):14451.

14. Mari D, Coppola R, Provenzano R. Hemostasis factors and aging. Exp Gerontol. 2008;43(2):66-73.

15. Tofler GH, Massaro J, Levy D, Mittleman M, Sutherland P, Lipinska I, Muller JE, D'Agostino RB. Relation of the prothrombotic state to increasing age (from the Framingham Offspring Study). Am J Cardiol. 2005;96(9):1280-3.

16. Zindovic I, Sjogren J, Bjursten H, Ingemansson R, Larsson M, Svensson PJ, Strandberg K, Wierup P, Nozohoor S. The role of von Willebrand factor in acute type A aortic dissection and aortic surgery. Thromb Res. 2019:178: 139-44.

17. Murray DJ, Brosnahan WJ, Pennell B, Kapalanski D, Weiler JM, Olson J. Heparin detection by the activated coagulation time: a comparison of the sensitivity of coagulation tests and heparin assays. J Cardiothorac Vasc Anesth. 1997;11(1):24-8

18. Weitz DS, Weitz JI. Update on heparin: what do we need to know? J Thromb Thrombolysis. 2010;29(2):199-207.

19. Hommos MS, Glassock RJ, Rule AD. Structural and functional changes in human kidneys with healthy aging. J Am Soc Nephrol. 2017;28(10):2838-44.

20. Neri E, Toscano T, Massetti M, Capannini G, Carone E, Tucci E, Diciolla F, Scolletta S, Morello R, Sassi C. Operation for acute type A aortic dissection in octogenarians: is it justified? J Thorac Cardiovasc Surg. 2001;121(2):259-67.

\section{Publisher's Note}

Springer Nature remains neutral with regard to jurisdictional claims in published maps and institutional affiliations.

\section{Submit your manuscript to a SpringerOpen ${ }^{\circ}$ journal and benefit from:}

- Convenient online submission

- Rigorous peer review

- Open access: articles freely available online

- High visibility within the field

- Retaining the copyright to your article

Submit your next manuscript at $\boldsymbol{\nabla}$ springeropen.com 